\title{
Equipment
}

\section{Invasive pressure monitoring of patients during magnetic resonance imaging}

Katherine H. Taber PhD,* Jeannie Thompson RN, $\ddagger$ Lewis A. Coveler MD, $\dagger$ L. Anne Hayman MD*
The purpose of this paper is to describe a system for monitoring patients who require general anaesthesia, profound sedation or intensive care while undergoing high field $(\geq 1.5 T)$ magnetic resonance (MR) imaging. Continuous evaluation of invasive and noninvasive pressures, inspired and end-tidal respiratory gas concentrations, body temperature, heart rate, ECG and pulse oximetry were measured successfully during the $M R$ examination. Diagnostic quality $M R$ images were acquired on all 15 monitored patients. The calculated signal-10-noise ratios were not different between the control and monitored patients. Commonly encountered technical problems and their solutions are described. This study demonstrates that invasive monitoring can be safely performed in critically ill patients who are undergoing high field MR examinations.

Cet article décrit un système de monitorage pour des patients soumis à une imagerie par résonance magnétique à champ de rayonnement de forte intensité $(\geq 1,5 T$ ) sous anesthésie générale, sédation profonde ou sous traitement aux soins intensifs. Pendant la résonance magnétique, on a accès à une lecture continue par voie directe ou indirecte des pressions sanguines, des concentrations inspirées et télé-expiratoires des gaz, de la température corporelle, de la fréquence cardiaque, et de l'oxymétrie pulsée. On obtient des images diagnostiques de qualité pour les 15 patients monitorés. Le rapport signal/bruit ne

\section{Key words}

ANAESTHESIA: diagnostic;

MEASUREMENT TECHNIQUES: nuclear magnetic resonance.

From the *Herbert J. Frensley Center for Imaging Research, Departments of Radiology and Anesthesiology, $†$ Baylor College of Medicine, Houston, Texas, and fOperative Services Department, Ben Taub General Hospital, Houston, Texas.

A patent is pending \#D-5451.

Address correspondence to: Dr. Katherine H. Taber, Department of Radiology, Baylor College of Medicine, One Baylor Plaza, Houston, Texas 77030, (713) 798-5146.

Accepted for publication 17th July, 1993. differe pas entre contrôles et patients monitorés. On rapporte les problèmes les plus fréquents et leurs solutions. Cette étude montre qu'on peut procéder en toute sécurité à des examens par résonance magnétique à champ de rayonnement de haute intensité même chez des grands malades.

There are two main types of difficulties encountered in extending clinical high field magnetic resonance (MR) examinations to patients who require general anaesthesia, profound sedation or intensive care. ${ }^{1}$ Problems can arise because the MR scanner environment alters the monitoring equipment or its signal. Thus, many clinical monitors do not function, or malfunction, when placed within the high magnetic field of an MR scanner.

There can also be problems in image quality caused by the effects of the monitoring equipment on the MR signals. The monitoring equipment can disrupt proper performance of the MR scanner in two ways. If the monitoring equipment contains a considerable amount of metal, its presence may subtly alter the magnetic field of the MR scanner, degrading the quality of the MR images. This can be compensated for by choosing a permanent location in the MR room for such equipment and reshimming the magnet to remove this influence. Small amounts of metal within probes can also create image artifacts if they are placed near the body part being imaged. 2,3 This can be corrected by moving the probe to a location well away from this area.

The monitoring equipment may also generate signals that interfere with or contaminate the MR signals. This causes artifacts to appear in the MR images. When this problem is suspected, MR images acquired with and without the presence of the monitoring equipment must be compared for both presence of artifact and for overall image quality (generally assessed by measuring the signalto-noise). ${ }^{4}$

Other problems occur when electrical artifacts and/ or heating is induced in the monitoring leads by the ra- 
diofrequency (RF) pulses and switching of gradients required to generate the MR image. Burns as a result of overheating in leads or probes have been reported. ${ }^{5}$ Risk to the patient from overheating is relatively easily avoided by insulating properly all leads and by assuring that the leads do not make a loop within the bore of the magnet. ${ }^{5}$ As an additional safety precaution, fibre optic probes should be used whenever possible. ${ }^{6}$ Problems with electrical artifacts are most troublesome in the electrocardiographic (ECG) signals. These difficulties can be minimized by grouping the electrodes closely together on the patient's back (usually only a few centimeter separation is needed). In addition, the ECG leads can be braided together. ${ }^{7}$

To overcome all these problems, a monitoring system can be purchased that is specifically made for the MR environment (In Vivo Research, Inc., Winter Park, FL; Nonin, Bruker Instruments, Germany). However, commercially available MR monitoring systems are expensive (approximately $\$ 28,000$ USD). A review of monitoring equipment which has been tested and found compatible with the MR environment has recently been published. ${ }^{2}$ They provide only noninvasive blood pressure measurements, electrocardiographic ECG measurements, respiration, heart rate and pulse oximetry. Inspired and endtidal anaesthetic gas concentrations and invasive blood and intraventricular pressures cannot be measured with these systems.

This paper summarizes our experience assembling an MR-compatible clinical physiological monitoring system which allows continuous monitoring of invasive, as well as noninvasive pressures, inspired and end-tidal gas $\left(\mathrm{CO}_{2}\right)$ concentration, body temperature, heart rate, pulse oximetry, and ECG. Patient support equipment included anaesthesia and mechanical ventilation is also assessed.

\footnotetext{
Methods

The components of the monitoring system used for this report are described in Table I. A schematic of this system is shown in the Figure. The only modifications required to adjust for the high MR environment consisted of lengthening cables and/or tubing to allow the monitors to be positioned at a distance from the MR scanner or outside the MR examination room. The oxygen saturation monitor (Criticare Systems, Inc.) had to stay within the MR examination room because the longest leads available were too short for it to be moved outside the room. It was, therefore, placed in front of the viewing window. This allowed it to be seen from the MR console. The preamplifier/telemetry unit for the LifeScope 11 system was mounted on a nonmagnetic intravenous stand and placed next to the patient bed, at the front of the magnet.
}

Only minor modifications of the MR examination room were required to install the monitoring equipment. A radiofrequency (RF) port, which consisted of copper tubing (1.5 inches internal diameter (ID) and three feet in length) was inserted through the shielding of the RF room and soldered into place. It provided a passage for the plastic hoses ( $8 \mathrm{~mm}$ ID) needed for end-tidal $\mathrm{CO}_{2}$ monitoring and noninvasive blood pressure measurement. A connector containing a RF low pass filter was installed in the filter plate of the MR examination room. The antenna for the LifeScope monitor was attached to this connector within the MR examination room. The signals were taken by cable from the connector on the outside of the room to the monitor located next to the MR console (see Figure).

Magnetic resonance imaging was performed with a 1.5 T Signa MR scanner (General Electric Co.). The standard clinical MR examination was done in a total of fifteen patients who required monitoring of either invasive blood pressure or inspired and end-tidal gas concentrations (monitored group). The medical records of these patients were examined for clinical diagnosis (see Table II). The results of these examinations were compared with those of seven patients undergoing the same types of MR examinations. In these control cases the only monitoring required was pulse oximetry.

The clinical image quality of each study was graded by one author (LAH). Image intensity measurements were made from regions of grey and white matter on 14 brain examinations (monitored $n=7$, control $n=$ 7). The signal-to-noise ( $\mathrm{S} / \mathrm{N}$ ) was calculated for both grey and white matter areas using the equation:

$\mathrm{S} / \mathrm{N}=\left(\mathrm{S}_{\mathrm{T}}-\mathrm{S}_{\mathrm{B}}\right) / \mathrm{S}_{\mathrm{B}}$

where $S_{T}$ is the measured intensity of the tissue and $S_{B}$ is the intensity of the background. ${ }^{4}$ Differences between the monitored and control groups were evaluated using the Mann Whitney U-test.

\section{Results}

Measurements were taken from normal volunteers prior to and following the installation of longer tubing and cables on the OR SARAcap (PPG Biomedical Systems) and the Dinamapp (Critikon, Inc.). No change in measurements were noted when the longer tubes or cables were used.

Fourteen adults and a nine-day-old infant were successfully monitored (Table II). Because the infant did not require tracheal intubation, the $\mathrm{PETCO}_{2}$ and the respiratory waveform were obtained using nasal prongs. A fibre optic pulse oximetry probe was required in this case because the patient was so small that the "non-fibre optic" probe on his toe entered the bore of the MR scanner 
TABLE I Components of the Permanent MR-Compatible Monitoring System*

\begin{tabular}{|c|c|c|}
\hline Instrument & Manufacturer & Variables measured \\
\hline $\begin{array}{l}1 \text { Lifescope } 11 \text { Patient Monitor } \\
\text { model OMP-7201C } †\end{array}$ & $\begin{array}{l}\text { Nihon Koden (America), Inc } \\
1652 \text { Deere Avenue } \\
\text { Irvine, CA } 92714\end{array}$ & $\begin{array}{l}\text { - ECG and heart rate } \\
\text { - } 2 \text { invasive blood pressures } \\
\text { - } 2 \text { temperatures } \\
\text { - respiratory rate and waveform } \\
\text { - arrhythmia detection }\end{array}$ \\
\hline $\begin{array}{l}2 \text { Oxygen Saturation Monitor } \\
501+\ddagger\end{array}$ & $\begin{array}{l}\text { Criticare Systems Inc. } \\
\text { P.O. Box } 26556 \\
\text { Milwaukee, WI } 53226\end{array}$ & - oxygen saturation \\
\hline 3 OR SARAcap & $\begin{array}{l}\text { PPG Biomedical Systems } \\
\text { P.O. Box } 15955 \text { Lenexa } \\
\text { Kansas } 66215\end{array}$ & $\begin{array}{l}\text { - inspired and end-tidal carbon } \\
\text { dioxide } \\
\text { - mean airway oxygen concentration } \\
\text { - respiratory rate } \\
\text { - carbon dioxide waveform }\end{array}$ \\
\hline 4 Dinamapp Monitor model 1846 & $\begin{array}{l}\text { Critikon, Inc. } \\
4110 \text { George Road } \\
\text { Tampa, FL } 33634\end{array}$ & $\begin{array}{l}\text { - noninvasive blood pressure } \\
\text { - pulse } \\
\text { - mean arterial pressure }\end{array}$ \\
\hline 5 SIMY-225 & $\begin{array}{l}\text { Monaghan, Inc. } \\
\text { Franklyn Building } \\
\text { Route } 9 \text { North } \\
\text { Plattsburgh NY } 12901\end{array}$ & - ventilator \\
\hline $\begin{array}{l}6 \text { Excel } 210 \mathrm{MRI} \text { compatible } \\
\text { anesthesia system§ }\end{array}$ & $\begin{array}{l}\text { Ohmeda } \\
\text { Ohmeda Drive } \\
\text { Madison, WI } 53707-7550\end{array}$ & - anaesthesia gas machine \\
\hline
\end{tabular}

*Patent pending, "Diagnostic Apparatus for Invasive Monitoring: \#D-5451."

tThis ICU monitor is no longer manufactured, but is available on the used equipment market. The Lifescope

ICU monitor has also been used successfully to monitor small animals in a $2.35 \mathrm{~T}$ scanner.

†Replaced by In Vivo Pulse Oximeter 4500 MRI Model 3109, In Vivo Research, Inc., 4420 Metric Drive, Suite A. Winter Park, Florida 32792.

§This anaesthesia system was modified with an Air-Shields Ventimeter Ventilator 11 from Air-Shields Vickers, Hatsboro, PA.

and created artifacts. In all cases, the quality of the physiological monitoring was adequate to allow proper patient management and excellent diagnostic MR images were obtained.

The average signal-to-noise in MR images acquired from control patients were the same as for the monitored patients for both grey and white matter for both types of MR acquisition used. In all cases statistical comparison indicated that the sampled populations were not different $(P>0.10)$. Specifically, on the $2500 / 80$ sequence, the measurements for grey matter were $37 \pm 9$ for control subjects and $31.7 \pm 12.9$ for the monitored patients. The white matter measured $29 \pm 6.3$ in controls and 25.4 \pm 10.2 for the monitored cases using this sequence. On the 500-800/17 sequence the grey matter was $36.8 \pm$ 15.3 in controls and $39.9 \pm 15.2$ in monitored patients. The white matter measured $39.5 \pm 1.6$ for the controls compared to $40.9 \pm 15.5$ for monitored cases.

\section{Discussion}

This study demonstrates the feasibility of monitoring invasive pressures in patients who require anaesthesia, profound sedation or intensive care during high field MR examination without degradation of the MR images. It was assembled from generally available commercial components. Only minimal modifications were required. The system allows reliable continuous evaluation of invasive and noninvasive blood pressure, inspired and end-tidal gas concentrations, body temperature, heart rate, ECG and pulse oximetry. It can be attached to the patient in 10-15 min. Approximately half of this setup time is outside the MR examination room.

The problems encountered in assembling this system were similar to those described by others. The major difficulty was placement of the RF port to allow passage of tubing and cables. This had to be done very carefully to protect the integrity of the RF shielded room. Since 
Diagram of System Layout

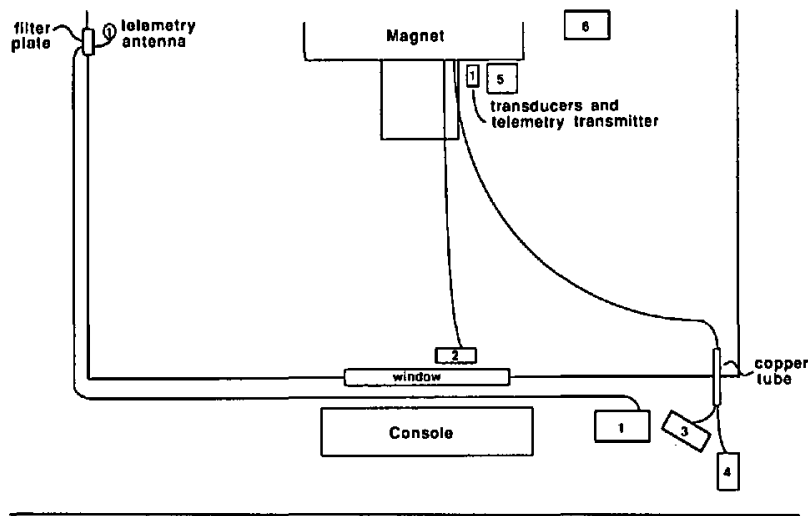

FIGURE Diagram of the radiofrequency (RF) shielded MR scan room shows the position of the magnet, monitoring, life support and anaesthesia systems. Each is numbered to match Table I. Note the anaesthesia gas machine (\#6) must remain in this position because the magnet was specifically adjusted to ignore the metal in this device.

TABLE II Summary of clinical diagnosis and parameters monitored in 15 patients.

\begin{tabular}{rll}
\hline Patient & Clinical diagnosis & Monitoring \\
\hline 1 & Parietal brain contusion with haernorrhage & {$[\mathrm{A}, \mathrm{C}]$} \\
2 & Brainstem infarct & {$[\mathrm{A}]$} \\
3 & Brainstem haematoma & {$[\mathrm{A}]$} \\
4 & Organic psychosis of unknown origin & {$[\mathrm{A}, \mathrm{B}]$} \\
5 & Acute meningitis with rapid deterioration & {$[\mathrm{A}, \mathrm{C}]$} \\
6 & Basal ganglia \& brainstem bleed, coma & {$[\mathrm{A}, \mathrm{D}, \mathrm{E}]$} \\
7 & Temporal lobe contusion, coma & {$[\mathrm{A}, \mathrm{D}]$} \\
8 & Closed head injury, right frontal lobectomy & {$[\mathrm{A}, \mathrm{D}]$} \\
9 & Coma, seizures, possible septic emboli & {$[\mathrm{A}, \mathrm{D}]$} \\
10 & Altered mental status, possible stroke & {$[\mathrm{A}, \mathrm{D}]$} \\
11 & Blunt trauma to head, seizures & {$[\mathrm{A}, \mathrm{B}]$} \\
12 & Altered mental status, seizures & {$[\mathrm{A}, \mathrm{D}]$} \\
13 & Sacral dimple & {$[\mathrm{A}, \mathrm{F}]$} \\
14 & Suspected middle cerebral artery dissection & {$[\mathrm{A}, \mathrm{B}, \mathrm{F}]$} \\
15 & Traumatic brain damage & {$[\mathrm{A}, \mathrm{B}]$} \\
\hline
\end{tabular}

A - Intubated and ventilated with end-tidal $\mathrm{CO}_{2}$ monitoring.

B - General anaesthesia.

C - Sedation.

D - Arterial line (invasive blood pressure)

E - Manual administration of Labetalol drip ( $80 \mathrm{mg} / 250 \mathrm{ml} \mathrm{D5W})$

and a Nipride drip ( $50 \mathrm{mg} / 250 \mathrm{ml}$ D5W).

F - Paediatric patient.

this is most easily done during initial construction, the addition of this specification is recommended when a new RF room is planned.

The authors hope that this report will encourage MR sites to install more extensive monitoring capability. The addition of this monitoring will allow the benefits of MR imaging to be enjoyed by patients who are often con- sidered too ill for imaging. The goal of monitoring is to simplify the challenges of proper patient monitoring in the MR environment by providing all the needed functions in a single setup.

This study demonstrates that invasive monitoring can be performed in critically ill patients who are undergoing a high field MR examination. The monitoring system described met the requirements for either inhaled or intravenous general anaesthesia or conscious sedation.

\section{Acknowledgments}

The authors thank the MR technical staff at Ben Taub General Hospital, Houston, TX. We also wish to acknowledge the technical expertise supplied by the Respiratory Therapy Department. Alteration of the RF room was kindly done by Wayne Barber, General Electric Field Engineering.

\section{References}

1 Patteson SK, Chesney JT. Anesthetic management for magnetic resonance imaging: problems and solutions. Anesth Analg 1992; 74: 121-8.

2 Kanal E, Shellock FG. Patient monitoring during clinical MR imaging. Radiology 1992; 185: 623-9.

3 Taber $K H$, Hayman $L A$. Temperature monitoring during MR imaging: comparison of fluoroptic and standard thermisters. J Magn Reson Imaging 1992; 2: 99-101.

4 Edelstein WA, Bottomly PA, Hart HR, Smith LS. Signal, noise, and contrast in nuclear magnetic resonance (NMR) imaging. J Comput Assist Tomogr 1983; 7: 391-401.

5 Shellock FG, Slimp GL. Severe burn of the finger caused by using a pulse oximeter during MR imaging (Letter). Am J Roentgenol 1989; 153: 1105.

6 Shellock FG, Myers SM, Kimble KJ. Monitoring heart rate and oxygen saturation with a fiber-optic pulse oximeter during MR imaging. Am J Roentgenol 1992; 158 : 663-4.

7 Rokey R, Wendt RE, Johnston DL. Monitoring of acutely ill patients during nuclear magnetic resonance imaging: use of a time-varying filter electrocardiographic gating device to reduce gradient artifacts. Magn Reson Med 1988; 6: 240-5. 